INDEPENDENT JOURNAL OF MANAGEMENT \& PRODUCTION (IJM\&P) http://www.ijmp.jor.br

v. 12, n. 1, January-February 2021

ISSN: 2236-269X

DOI: 10.14807/ijmp.v12i1.1295

\title{
A METHOD TO SOLVE TWO-PLAYER ZERO-SUM MATRIX GAMES IN CHAOTIC ENVIRONMENT
}

\author{
Hamiden Abd El- Wahed Khalifa \\ Mathematics Department, College of Science and Arts, Qassim \\ University, Saudi Arabia \\ Operations Research Department, Faculty of Graduate Studies for \\ Statistical Research, Cairo University, Egypt \\ E-mail: hamiden_2008@yahoo.com \\ Pavan Kumar \\ Department of Mathematics, School of Advanced Science and \\ Languages, VIT Bhopal University, India \\ E-mail:pavankmaths@gmail.com \\ Submission: $2 / 29 / 2020$ \\ Revision: 3/19/2020 \\ Accept: 3/29/2020
}

\section{ABSTRACT}

This research article proposes a method for solving the two-player zero-sum matrix games in chaotic environment. In a fast growing world, the real life situations are characterized by their chaotic behaviors and chaotic processes. The chaos variables are defined to study such type of problems. Classical mathematics deals with the numbers as static and less value-added, while the chaos mathematics deals with it as dynamic evolutionary, and comparatively more value-added. In this research article, the payoff is characterized by chaos numbers. While the chaos payoff matrix converted into the corresponding static payoff matrix. An approach for determining the chaotic optimal strategy is developed. In the last, one solved example is provided to explain the utility, effectiveness and applicability of the approach for the problem.

Keywords: Chaos numbers; Static number; Matrix game; Linear programming, Payoff matrix.

Abbreviations: $\mathrm{DM}=$ Decision Maker; $\mathrm{MCDM}=$ Multiple Criteria Decision Making; LPP = Linear Programming Problem; GAMS= General Algebraic Modeling System. 
ISSN: $2236-269 X$

DOI: 10.14807/ijmp.v12i1.1295

\section{INTRODUCTION}

The theory of games is considered as a technique based on mathematical modeling. The applications of theory of games are in multiple criteria decision makings (MCDM). In MCDM, there are multiple decision makers (DM) in the situation of cooperation or conflict with each other. The game is being played by each DM to overcome their opponents (Khalifa, 2019). The theory of game supports a large number of techniques and tools, which are very efficient and effective.

These techniques and tools are applied to derive the multiple person ith strategies, and to solve analytically. These strategies are considered in tractions among multi rational decision makers (Krishnaveni \& Ganesan, 2018). There are a wide number of applications of the theory of games, for example, economic control problems, financial management, social and financial policies (Von Neumann \& Morgenstern, 1944).

The concepts of the game theory provide a common language to formulate structurer, analyze, and eventually understand different strategic scenarios (Bhuiyan, 2018). The ordinary conditions were introduced, which are necessary as well as sufficient; in order to compare the structures of information in the zero-sum games (Peski, 2008).

These games are presented with the help of ordinary theory of games. Assumption is that all the data regarding the game are determined exactly by players. There exist a large number of games, where the players are unable to determine exactly, some data in the real life environment. For this type of game, the imprecision occurs as a result of inaccuracy in the input data as well as the vague comprehension of the environment to the players (Berg \& Engel, 1998). Accordingly, several mathematicians have attempted to contribute and introduce a number of procedures to find the stable strategies in case of this type of games (Takahashi, 2008).

The games, where the players are unable to determine exactly, can be determined exactly with the help of fuzzy sets (Zadeh, 1965). Later, a fuzzification principle was proposed, which was further developed to use the fuzzy numbers in place of real numbers (Dubois \& Prade, 1980). The conception of optimal decision making strategy was proposed when the goals are conflicting (Bellman \& Zadeh, 1970).

Some studies were conducted on the cooperative game theory, and he merged this with fuzzy set theory to provide an improved a method for optimization as cooperative fuzzy games (Dhingra \& Rao, 1995). They presented a computational method for solving the multiple 


\section{INDEPENDENT JOURNAL OF MANAGEMENT \& PRODUCTION (IJM\&P)}

http://www.ijmp.jor.br

v. 12, n. 1, January-February 2021

ISSN: 2236-269X

DOI: 10.14807/ijmp.v12i1.1295

objective optimization models. Fuzzy games were further studied by many researchers (Selvakumari \& Lavanya, 2015; Thirucheran, Meena, \& Lavanya, 2017). The strategies consisted of expected equilibrium and $r$-trust maxi-min, were developed by introducing an operator generated by the trust measure of variables in rough environment, and expected value (Xu \& Yao, 2010). Some researchers studied the complete decision set for the generalized symmetric fuzzy linear programming problem (Zhao, Govind \& Fan, 1992)

A game problem was presented by considering the concept of fuzzy in the payoffs and goals , and was solved by an application of fuzzy linear programming (Campos, 1989). The principle of max-min was applied to propose the single as well as multiple objective matrix games with fuzzy payoffs and goals (Sakawa \& Nishizaki, 1994). It was demonstrated that a two-person zero-sum matrix game with fuzzy payoffs and goals is equivalent to two linear programming problems (LPPs) (Bector, Chandra \& Vijay, 2004, 2004a). Each problem is the dual to the other in fuzzy environment. To study the game problem, the concepts of fuzzy relation approach, fuzzy duality and ranking function were applied in matrix game problems (Vijay, Chandra \& Bector, 2005; Vijay et al., 2007).

Some vague payoffs multiple objective matrix game were solved by using a new order function (Pandey \& Kumar, 2010). The fuzzy matrix games were extensively studied to propose a method based on Lexicographic. This method was used to determine the solution of such games (Nan, Li \& Zhang, 2010). To solve the fuzzy matrix game, many solution methods were developed, which were based on the concept of signed distance, parametric representation of interval numbers (Sahoo, 2015; 2017).

The constrained matrix games were studied by using the payoffs based on triangular fuzzy numbers as well the concept of trapezoidal fuzzy numbers ( $\mathrm{Li} \&$ Hong, 2012; Bandyopadhyay \& Nayak, 2013). Later, the concept of intuitionistic fuzzy numbers was derived to introduce the payoffs for the fuzzy matrix games (Bandyopadhyay \& Nayak, 2013).

The matrix games with triangular membership function were studied (Chen \& Larboni, 2006), where the two person zero-sum fuzzy matrix game was solved by using the linear programming (LP) model. The trapezoidal fuzzy numbers were used to represent the payoff of matrix games. A fast approach was proposed to solve the matrix games with payoffs of trapezoidal fuzzy numbers (Kumar, Chopra \& Saxena, 2016). 
INDEPENDENT JOURNAL OF MANAGEMENT \& PRODUCTION (IJM\&P)

http://www.ijmp.jor.br

v. 12, n. 1, January-February 2021

ISSN: 2236-269X

DOI: 10.14807/ijmp.v12i1.1295

Recently, a zero-sum matrix game model with Dmpster-Shafer belief structure payoffs was developed, and a decomposition method was proposed to calculate the value of such a game which is expressed with belief structures (Deng, Jiang \& Zhang, 2017). An alternating method was developed to solve the matrix games (Seikh, Nayak \& Pal, 2013). The fuzzy matrix games are with very high degree of inconsistent information and indetermination. Very recently, the two-player zero-sum games were studied by several researchers. A method to solve the fuzzy matrix games was presented, which was based on the concept of neutrosophic sets (Khalifa, 2019).

The repeated two-player zero-sum game with private monitoring was considered and it was shown that even the players have unequal and time-varying discount factors (Carmona \& Carvalho, 2016). The payoff of each player is equal to his stage-game mini-max payoff in every sequential equilibrium. The fuzzy games with pure as well as mixed strategies were presented. However, the noncooperation between players was in vague environment (Parthasarathy \& Raghavan, 2010).

The natural forces and processes are uncertain as well as infinite. Therefore, the natural forces interact with other in a chaotic fashion, following a spontaneous order, which is chaos. Chaos is treated as the ordered disorder of nature. The classical definition of order is short-term based, since it doesn't permit the evaluation or the change. Although, nature is always in change in a continuous manner, in progress, and in evaluation because it is governed by infinity of dimensions regarding the time, space, and state (Ketata, Satish \& Islam, 2006). The knowledge of nature requires the development of new concepts and tools to study in a better way, its variables and process and their diverse interaction (Gutzwiller, 1991; Strogatz, 2001). The chaos and fractals were studied with their application in diverse fields (Peitgen, Jurgens \& Saupe, 2004).

The remainder of the research article is structured as follows: Section 2 presents the preliminaries required for the chaos numbers. In section 3, a two-person zero-sum game problem with chaos numbers is formulated. Section 4 introduced a proposed method to solve the matrix game. One solved example is presented in Section 5 , to show the efficiency of the proposed solution method. At last, section 6 concludes this paper.

\section{PRELIMINARIES}

In this section, some basic definition of the two- player zero-sum game and the arithmetic operations related to chaos number are recalled (Luce \& Raiffa, 1957; Lui, 2002). 
Definition 1. (KETATA; SATISH; ISLAM, 2006). (Chaos number). A chaos number $\mathrm{x}_{\mathrm{a}}$ is neither static nor rigid. It changes over time as well as in space.

Definition 2. (KETATA; SATISH; ISLAM, 2006). Suppose $\mathrm{x}_{\mathrm{a}}$ and $\mathrm{y}_{\mathrm{b}}$ be two chaos numbers. The arithmetic operations on $\mathrm{x}_{\mathrm{a}}$ and $\mathrm{y}_{\mathrm{b}}$ are:
a) $\quad x_{a}+y_{b}=(x+y)_{a+b}$,
b) $\mathrm{x}_{\mathrm{a}}-\mathrm{y}_{\mathrm{b}}=(\mathrm{x}-\mathrm{y})_{\mathrm{a}-\mathrm{b}}$,
c) $\mathrm{x}_{\mathrm{a}} \times \mathrm{y}_{\mathrm{b}}=(\mathrm{x} \times \mathrm{y})_{\mathrm{bx}+\mathrm{ay}+\mathrm{ab}}$,
d) $\mathrm{x}_{\mathrm{a}} \div \mathrm{y}_{\mathrm{b}}=\left(\frac{\mathrm{x}}{\mathrm{y}}\right)_{\mathrm{u}}$, where $u=\frac{(x+a) \times y-x \times x(y+b)}{(y+b) \times y}$,
e) $\quad 0_{\mathrm{a}} \times \mathrm{x}_{\mathrm{b}}=0_{\mathrm{ax}+\mathrm{ab}}$,
f) $0_{\mathrm{a}} \div \mathrm{x}_{\mathrm{b}}=0_{\left(\frac{\mathrm{a}}{\mathrm{s}+\mathrm{b}}\right)}$
g) $\quad \mathrm{x}_{\mathrm{a}} \div \mathrm{0}_{\mathrm{b}}=(\mathrm{b} \times \mathrm{x})_{\mathrm{ab}}$.

\section{DESCRIPTION OF THE PROPOSED PROBLEM}

In this section, we propose the two-player zero-sum game problem, which is the simple and classical problem in the theory of games. In this problem, the gain of one player is equal to the loss of other player. There are three types of two-person zero- sum chaos numbers matrix games:

Type -1: Matrix games with chaotic goals.

Type -2: Matrix games with chaotic payoffs.

Type -3: Matrix games with chaotic goals as well as chaotic payoffs.

Let us discuss a two-person zero-sum game, where the each entry in the payoff matrix $\tilde{A}$ is chaos number. Therefore, the chaos payoff matrix is given by:

$$
\begin{aligned}
& \text { Player II }
\end{aligned}
$$

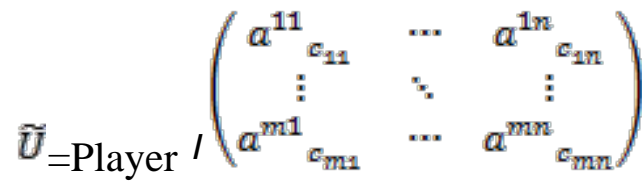


DOI: 10.14807/ijmp.v12i1.1295

Players I and II have $\mathrm{n}$ and $\mathrm{m}$ strategies, represented by P, and Q, respectively and are defined as

$$
P=\left\{x \in \mathbb{R}^{m}: x_{i} \geq 0, \sum_{i=1}^{m} x_{i}=1\right\},
$$

Moreover,

$$
Q=\left\{y \in \mathbb{R}^{n}: y_{j} \geq 0, \sum_{j=1}^{n} y_{j}=1\right\} \text {. }
$$

For the players I, and II, the expressions for the statistical expectations are, respectively, given by:

$$
\begin{aligned}
Z_{c} & =\sum_{j=1}^{n} \sum_{i=1}^{m} x_{i} a^{i j}{ }_{c_{i j}} y_{j} \\
\text { and } \quad Z_{c} & =\sum_{i=1}^{m} \sum_{j=1}^{n} x_{i} a^{i j}{ }_{c_{i j}} y_{j} .
\end{aligned}
$$

Where, ${ }^{i j}{ }_{c_{i j}}\left(i=1,2, \ldots, m_{;} j=1,2, \ldots, n\right)$ are characterized by numbers

Definition 3. (XU; YAO, 2010). (Saddle point):

The saddle point exists for a game when the max-min value is equal to the min-max value. The value of the saddle point is referred as the value of the concerned game. Once the saddle point exists, the corresponding strategies are referred as the optimal strategies.

The two statistical expectations are the equal, because the corresponding sums are finite. Also, because of vagueness in payoffs chaos numbers, it is complicate for the persons to select the optimal strategy. Therefore, we concentrate with the objective on how to maximize player's or minimize the opponent's fuzzy payoffs. On the basis of this idea, let us focus on the maximum equilibrium strategy as described in the following definition.

Definition4. (XU; YAO, 2010). In a two-player zero-sum game, player I’s mixed strategy $x^{*}$ player II’s mixed strategy $y^{*}$ are termed as to be the chaos optimal strategies when

$$
x^{T} A_{c} y^{*} \leq x^{* T} A_{c} y^{*} \leq x^{* T} A_{c} y,
$$

for any mixed strategies $\mathrm{x}$ and $\mathrm{y}$.

The optimal strategy, in chaotic sense, of player I is the strategy that maximizes $Z_{c}$ irrespective of II's strategy. Moreover, the optimal chaotic strategy of player II is the strategy that minimizes $Z_{c}$ irrespective of I's strategy. 
Based on the static numbers of each chaotic payoff $a^{i j}{ }_{c_{i j}}$, which denoted by $\left(a^{i j}+c_{i j}\right)$, the chaos pay-off matrix as represented by (1) is transformed to matrix game of classical payoff as follows:

$$
\begin{gathered}
\text { Player II } \\
U_{=\text {Player }} I\left(\begin{array}{ccc}
a^{11}+c_{11} & \cdots & a^{1 n}+c_{1 n} \\
\vdots & \ddots & \vdots \\
a^{m 1}+c_{m 1} & \cdots & a^{m n}+c_{m n}
\end{array}\right)
\end{gathered}
$$

Now, a game with static payoff matrix (5) is considered with the mixed strategies for the players I and II as given in (2) and (3), in a respective manner. When F is equal to the optimum game value for the player II, the linear programming model (LPP) for player II is given by

\section{Minimize $\mathrm{F}$}

Such that

$$
\sum_{j=1}^{n} y_{j} \leq F ; y_{j} \geq 0, j=1,2, \ldots, n \text {. }
$$

By putting $y_{j}^{r}=\frac{y_{j}}{F}$, the problem (7) becomes

$$
\max _{j=1}\left(\sum_{j=1}^{n} y_{j}^{\prime}\right)
$$

Subject to

$$
\sum_{j=1}^{n}\left(a^{i j}+c_{i j}\right) y_{j} \leq 1 ; y_{j}^{\sigma} \geq 0, j=1,2, \ldots, n .
$$

Proceeding in the same way, the linear programming model for player I, is given by

$$
\text { Maximize G }
$$

Such that

$$
\sum_{i=1}^{m}\left(a^{i j}+c_{i j}\right) x_{i} \geq G ; x_{i} \geq 0, i=1,2, \ldots, m
$$

Substituting $x_{i}^{r}=\frac{x_{i}}{G}, i=1,2, \ldots, m$. Then problem (9) becomes

$$
\min _{i}\left(\sum_{i=1}^{m} x_{i}\right)
$$

Subject to

$$
\sum_{i=1}^{m}\left(a^{i j}+c_{i j}\right) x_{i}^{r} \geq 1, x_{i}^{*} \geq 0, i=1,2, \ldots, m
$$


DOI: 10.14807/ijmp.v12i1.1295

\section{SOLUTION METHOD}

In this section, we describe the steps of solution method for solving the proposed game problem as follows:

Step 1: Convert chaotic payoff $a^{11} c_{11}$ in (1) and determine static matrix game (6).

Step 2: Transform the payoff matrix (6) to the concerned problems (7) and (9).

Step 3: Apply the linear programming models (8), and (10) for the problems (7) and (9).

Step 4: Using the package (GAMS) or Simplex method, we solve problem (8), and problem (10), to determine the chaotic optimum strategies and the value of the chaotic matrix game for persons II and I.

\section{SOLVED EXAMPLE}

Consider the pay-off matrix for the concerned game as:

$$
A_{c}=\left(\begin{array}{cccc}
4_{0} & 2_{1} & 5_{0} & 5_{1} \\
10_{1} & 9_{3} & 7_{2} & 10_{0} \\
1_{\mathrm{n}} & 2_{\mathrm{n}} & 17_{2} & 6_{1}
\end{array}\right)
$$

The corresponding static two- person zero- sum matrix game is

$$
A=\left(\begin{array}{cccc}
4 & 3 & 5 & 6 \\
11 & 12 & 9 & 10 \\
1 & 2 & 19 & 7
\end{array}\right)
$$

According to the problem (8), we obtain the following optimization problem:

$$
\max \left(y_{1}^{\circ}+y_{2}^{\circ}+y_{3}^{\circ}+y_{4}^{\circ}\right)
$$

Subject to

$$
\begin{aligned}
& 4 y_{1}^{\circ}+3 y_{2}^{\circ}+5 y_{3}^{\circ}+6 y_{4}^{\circ} \leq 1, \\
& 11 y_{1}^{\circ}+12+9 y_{3}^{\circ}+10 y_{4}^{\circ} \leq 1, \\
& 1 y_{1}^{\circ}+2 y_{2}^{\circ}+19 y_{3}^{\circ}+7 y_{4}^{\circ} \leq 1 \\
& y_{1}^{\circ}, y_{2}^{\circ}, y_{3}^{\circ}, y_{4}^{\circ}
\end{aligned}
$$

The optimal strategy for player II is: $y_{1}^{\sigma}=0, y_{2}^{\circ}=0, y_{3}^{\circ}=0.231, y_{4}^{\circ}=0.769$, and the corresponding game value equal to 9.769

Referring to problem (10), we have 
ISSN : 2236-269X

DOI: 10.14807/ijmp.v12i1.1295

$$
\min \left(x_{1}^{\circ}+x_{2}^{\circ}+x_{3}^{\circ}\right)
$$

Subject to

$$
\begin{aligned}
4 x_{1}^{\prime}+11 x_{2}^{\prime}+1 x_{3}^{\prime} & \geq 1, \\
3 x_{1}^{\prime}+12 x_{2}^{\prime}+2 x_{3}^{\prime} & \geq 1, \\
5 x_{1}^{\prime}+9 x_{2}^{\prime}+19 x_{3}^{\prime} & \geq 1, \\
6 x_{1}^{\prime}+10_{2}^{\prime}+7 x_{3}^{\prime} & \geq 1, \\
x_{1}^{\prime}, x_{2}, x_{3}^{\prime} & \geq 0
\end{aligned}
$$

The optimal strategy for player I is: $x_{1}^{\sigma}=0, x_{2}^{\sigma}=0.923, x_{3}^{\sigma}=0.077$, and the corresponding game value equal to 9.769 .

Thus, the chaotic optimal strategy is as in the following table

Table 1: Chaotic optimal strategy

\begin{tabular}{|c|c|c|}
\hline Player -I & Player-II & Value of Game \\
\hline$x_{2}^{r}=0.923_{0}$ & $y_{1}^{r}=0_{0}$ & $9.248018_{1.940787}$ \\
$x_{3}^{r}=0.077_{0}$ & $y_{2}^{r}=0_{0}$ & \\
$\|$ & $y_{3}^{r}=0.231_{0}$ & \\
\hline & $y_{4}^{r}=0.769_{0}$ & \\
\hline
\end{tabular}

\section{CONCLUSIONS}

In this research article, we presented a two-player zero-sum matrix game by introducing the concept of chaos numbers. In the beginning, we proposed the game with chaos numbers payoffs. Thereafter, we proposed an equilibrium strategy, following the solution method. One numerical example is given to illustrate the proposed research method. In this research article, only one kind of games with uncertain payoffs is studied. The results obtained are displayed in the table. However, in real life situations, there exist such games with random payoffs. Therefore, as a possible direction for future research, one can extend this paper by considering the random pay-offs.

\section{REFERENCES}

Bandyopadhyay, S., Nayak, P. K., \& Pal, M. (2013) Solution of matrix game with triangular intuitionistic fuzzy pay-off using score function. Open Journal of Optimization, 2(1), 9-15. DOI: 10.4236/ojop.2013.21002

Bandyopadhyay, S., \& Nayak, P. K. (2013) Matrix games with trapezoidal fuzzy payoff. International Journal of Engineering Research and Development, 5, 21- 29. 
Bector, C. R., \& Chandra, S., Vijay, (2004) Duality in linear programming with fuzzy parameters and matrix games with fuzzy payoffs. Fuzzy Sets and Systems, 146, 253-269. DOI: 10.1016/S0165-0114(03)00260-4

Bector, C. R., \& Chandra, S., Vijay, (2004a) Matrix games with fuzzy goals and fuzzy linear programming duality. Fuzzy Optimization and Decision Making, 3(3), 255-269. DOI: 10.1023/B:FODM.0000036866.18909.f1

Bellman, R. E., \& Zadeh, L. A. (1970) Decision making in a fuzzy environment. Management Science, 17(4), 141-164. DOI: 10.1287/mnsc.17.4.B141

Berg, J., \& Engel, A. (1998) Matrix games, mixed strategies, and statistical mechanics. Physical Review Letters, 81(22), 4999-5002. DOI: 10.1103/PhysRevLett.81.4999

Bhuiyan, B. A. (2018) An overview of game theory and some applications. Philosophy and Progress, 59(1-2), 111-128. DOI: 10.3329/pp.v59i1-2.36683

Campos, L. (1989) Fuzzy linear programming models to solve fuzzy matrix games. Fuzzy Sets and Systems, 32(3), 275-289. DOI: 10.1016/0165-0114(89)90260-1

Camona, G., \& Carvalho, L. (2016) Repeated two-person zero-sum games with unequal discounting and private monitoring. Journal of Mathematical Economics, 63(C), 131-138. Available: http://www.sciencedirect.com/science/article/pii/S0304406816000136. DOI: 10.1016/j.jmateco.2016.02.005

Chen, Y- W., \& Larboni, M. (2006) Two-person zero-sum game approach for fuzzy multiple attribute decision-making problem. Fuzzy Sets and Systems, 157(1), 34-51. DOI: 10.1016/j.fss.2005.06.004

Deng, X., Jiang, W., \& Zhang, J. (2017) Zero-sum matrix game with payoffs of DempsterShafer belief structures and its applications on sensors. Sensors, 17(4), 922. DOI: 10.3390/s17040922.

Dhingra, A. K., \& Rao, S. S. (1995) A cooperative fuzzy game theoretic approach to multiple objective design optimizations. European Journal of Operational Research, 83(3, p. 547567. DOI: 10.1016/0377-2217(93)E0324-Q

Dubois, D., \& Prade, H. (1980) Possibility Theory: An approach to computerized processing of uncertainty, Plenum, New York.

Gutzwiller, M. C. (1991) Chaos in classical and quantum mechanics. Interdisciplinary Applied Mathematics, Springer, New York, NY.

Ketata, C., Satish, M. G., \& Islam, M. R. (2006) Chaos numbers. In: International Conference On Computational Intelligence For Modeling Control And Automation (CIMCA), IEEE, Proceedings, Sydney, Australia. DOI: 10.1109/CIMCA.2006.132

Khalifa, H. A. (2019) An approach for solving two- person zero- sum matrix games in neutrosophic environment. Journal of Industrial and Systems Engineering, 12(2), 186-198. Available: http://www.jise.ir/article_87288.html

Krishnaveni, G., \& Ganesan, K. (2018) New approach for the solution of two person zero sum fuzzy games. International Journal of Pure and Applied Mathematics, 119(9), 405-414. Available: https://acadpubl.eu/jsi/2018-119-9/articles/9/39.pdf

Kumar, S., Chopra, R., \& Saxena, R. R. (2016) A fast approach to solve matrix games with payoffs of trapezoidal fuzzy numbers. Asia-Pacific Journal of Operational Research, 33(06), 1650047. DOI: 10.1142/S0217595916500470 
DOI: 10.14807/ijmp.v12i1.1295

Li, F. D., \& Hong, X. F. (2012) Solving constrained matrix games with payoffs of triangular fuzzy numbers. Computers \& Mathematics with Applications, 64(4), 432-448. DOI: 10.1016/j.camwa.2011.12.009

Liu, B. (2002) Theory and practice of uncertain programming, Physica, New York, NY, USA.

Luce, R., \& Raiffa, H. (1957) Games and decision, John Wiley \& Sons, New York, NY, USA.

Nan, R., Li, D. F., \& Zhang, M. J. (2010) A Lexicographic method for matrix games with payoffs of triangular intuitionistic fuzzy numbers. International Journal of Computational Intelligence Systems, 3(3), 280-289. DOI: 10.1080/18756891.2010.9727699

Pandey, D., \& Kumar, S. (2010) Modified approach to multiobjective matrix game with vague payoffs. Journal of International Academy of Physical of Sciences, 14(2), 149-157.

Parthasarathy, T., \& Raghavan, E. T. (2010) Some topics in two-person games. American Elsevier Publishing, NEW York, NY, USA, 1971.

Peitgen, H- O., Jurgens, H., \& Saupe, D. (2004) Chaos and fractals, $2^{\text {nd }}$ Edition, Springer, New York, NY.

Peski, M. (2008) Comparison of information structures in zero- sum games. Games and Economic Behavior, 62(2), 732-735. DOI: 10.1016/j.geb.2007.06.004. Available: https://www.sciencedirect.com/science/article/abs/pii/S0899825607001169.

Sahoo, L. (2015) An interval parametric technique for solving fuzzy matrix games. Elixir Applied Mathematics, 93, 39392-39397. Available: https://www.elixirpublishers.com

SAHOO, L. (2017) An approach for solving fuzzy matrix games using signed distance method. Journal of Information and Computing Science, 12(1), 073-080. Available: https://pdfs.semanticscholar.org/149a/eddfb9fd64ebf522fd424c404071d41c49ec.pdf

Sakawa, M., \& Nishizaki, I. (1994) Max-min solutions for fuzzy multiobjective matrix games. Fuzzy Sets and Systems, 67(1), 53-69. DOI: 10.1016/0165-0114(94)90208-9. Available: https://www.sciencedirect.com/science/article/abs/pii/0165011494902089.

Seikh, M. R., Nayak, K. P., \& Pal, M. (2013) An alternative approach for solving fuzzy matrix games. International Journal of Mathematics and Soft Computing, 5(1), 79-92.

Selvakumari, K., \& Lavanya, S. (2015) An approach for solving fuzzy game problem. Indian Journal of Science and Technology, 8(15), 1-6. DOI: 10.17485/ijst/2015/v8i15/56807

Strogatz, S. H. (2001) Nonlinear dynamic and chaos: with applications to physics, biology, chemistry, and engineering, Preseus Books Group, New York, NY.

Takahashi, S. (2008) The number of pure nash equilibria in a random game with nondecreasing best responses. Games and Economic Behavior, 63(1), 328-340. DOI: 10.1016/j.geb.2007.10.003

Thirucheran, M., Meena, R. E., \& Lavanya, S. (2017) A new approach for solving fuzzy game problem. International Journal of Pure and Applied Mathematics, 114(6), 67-75.

Available: https://acadpubl.eu/jsi/2017-114-5/articles/2/8.pdf

Vijay, V., Chandra, S., \& Bector, C. R. (2005) Matrix games with fuzzy goals and fuzzy payoffs. Omega, 33(5), 425-429. DOI: 10.1016/j.omega.2004.07.007 
Vijay, V., Mehra, A., Chandra, S., \& Bector, C. R. (2007) Fuzzy matrix games via a fuzzy relation approach. Fuzzy Optimization and Decision Making, 6, 299-314. DOI: 10.1007/s10700-007-9015-9

Von Neumann, J., \& Morgenstern, D. (1944) The theory of games in economic behavior, Wiley, New York.

$\mathrm{Xu}, \mathrm{J}$. (1998) Zero sum two-person game with grey number payoff matrix in linear programming. The Journal of Grey System, 10(3), 225-233. DOI:

Xu, J., \& Yao, L. (2010) A class of two-person zero-sum matrix games with rough payoffs. International Journal of Mathematics and Mathematical Sciences, 22. DOI: 10.1155/2010/404792

Zadeh, L. A. (1965) Fuzzy sets. Information Control, 8(3), 338- 353.

Zhao, R., Govind, R., \& Fan, G. (1992) The complete decision set of the generalized symmetrical fuzzy linear programming problem. Fuzzy Sets and Systems, 51(1), 53-65. DOI: 10.1016/0165-0114(92)90075-F 